\title{
Should we legalise cannabis?
}

\author{
Fiona Godlee editor in chief
}

The BMJ

In any public debate there may come a point when the evidence for a shift in direction clearly outweighs that against. Has this point been reached for drug policy reform?

Several UK medical bodies have decided it has. The Royal College of Physicians of London, the Faculty of Public Health, and the Royal Society for Public Health all now support decriminalising non-medical use of drugs such as cannabis, cocaine, and heroin. In this they agree with the World Health Organization and the UK government's own independent Advisory Council on the Misuse of Drugs. The other medical royal colleges and the BMA have no official position. In 2016 the BMA's annual representative meeting called for legislation to prioritise treating rather than criminalising drug users, but a motion in 2018 to publicly support decriminalisation was defeated. The BMJ has called for a regulated legal market in currently illegal drugs for any use (doi:10.1136/bmj.k2057; doi:10.1136/bmj.i6067; bmj.com/war-on-drugs).

Of the royal colleges with no official position, three might be said to represent doctors working at the sharpest end of the war on drugs: those of general practitioners, emergency medicine, and psychiatrists. Their views therefore hold particular sway, especially the psychiatrists, and especially among politicians, whose fear of public opinion on this issue was recently reaffirmed when Conservative leadership candidates rushed to endorse the current law despite their own admissions of previous drug taking (https://blogs.bmj.com/bmj/2019/06/19/drugs-aredecriminalised-in-the-uk-if-you-are-a-white-privileged-mp). So a debate held this week at the annual meeting of the Royal College of Psychiatrists on whether cannabis supply should be legalised is an important event. We carry both sides of the debate (doi:10.1136/bmj.14468).

It's interesting to see where the battle lines are drawn. Both sides agree on the greatly increased risk of psychosis from daily use of high potency cannabis, of the sort that is widely available in the UK. But what would be the effect of legalisation? Molly Meacher and colleagues cite evidence that low potency cannabis can be consumed safely and conclude that a state controlled, regulated market would protect health as well as raising tax revenues. They would set age and potency limits and ban advertising. Robin Murray and Adam Grindley concede that legalisation wouldn't necessarily increase use and potency, but they want to wait and see what happens in the US and Canada. In the meantime they support decriminalisation of people who take drugs.

Perhaps the Royal College of Psychiatrists will take courage from this and follow suit. 